\title{
MYOSITIS OSSIFICANS PROGRESSIVA: CASE REPORT
}

Frederico Barra de Moraes' ${ }^{1}$ Alano Ribeiro de Queiroz Filho ${ }^{2}$, Leonardo Jorge da Silva² ${ }^{2}$ Válney Luiz da Rocha ${ }^{3}$, Nayara Portiliho Araújo ${ }^{4}$, Ernesto Quaresma Mendonça ${ }^{4}$, Érica Paiva de Almeida ${ }^{4}$

\section{ABSTRACT}

Myositis ossificans progressiva is a rare autosomal dominant disease with less than 1,000 case reports. Such patients present edema, caused by inflammatory processes that progressively calcify, and with loss of mobility in the region affected. The objective of this study was to describe a case of myositis ossificans progressiva, present its clinical manifestations and discuss the treatments available (oral ascorbic acid and intravenous bisphosphonate).

Keywords - Myositis Ossificans; Ascorbic Acid; Ossification, Heterotopic; Bisphosphonates

\section{INTRODUCTION}

Myositis ossificans progressiva (MOP), also known as fibrodysplasia ossificans progressiva (FOP), is a rare disease with less than 1,000 cases described. It is an autosomal dominant condition that varies in prominence, with sporadic cases ${ }^{(1)}$. The process of heterotopic bone formation involves tendons, fascias, aponeuroses and muscles.

It was described for the first time by Patin ${ }^{(2)}$. Its physiopathology remains incompletely understood. The soft tissues become affected by edema, and the back of the neck is the region most frequently involved ${ }^{(3)}$. This edema, from inflammatory processes, gradually becomes calcified, with loss of mobility in the affected region. Repeated trauma may trigger the process.

Many treatments have been used, such as steroids, isotretinoin and oral etidronate, but without good results $^{(4-6)}$. In vitro chemical studies have shown that bisphosphonates adsorb hydroxyapatite crystals, thus diminishing heterotopic bone formation during the active stage of the disease ${ }^{(7)}$. Palhares ${ }^{(8)}$ observed that high doses of ascorbic acid controlled the progression of the disease.
The aim of this study was to report on a case of MOP, present the clinical manifestations and discuss the treatments available.

\section{CASE REPORT}

The patient was a 21-year-old man who was attended at the Department of Orthopedics of the Clinical Hospital of the School of Medicine, Federal University of Goiás. He had presented hardened tumor growths and deformities since birth, but they had worsened greatly during his adolescent growth, from the age of eight years onwards. He complained of pain and movement difficulties, along with short thumbs.

He presented multiple contractures in his upper limbs, lower limbs and spine. His posture was scoliotic, with a high degree of thoracic lordosis, dorsolumbar stiffness and cervical stiffness. His left scapula was protruded, and he had ectopic ossifications in the paravertebral musculature. He had difficulty in opening his mouth, swallowing food and performing thoracic inspiration.

His hips and shoulders were stiff bilaterally, with atrophied deltoid, trapezoid, biceps, triceps, middle

1 - Substitute Assistant Professor of Orthopedics in the Department of Orthopedics and Traumatology, Clinical Hospital of the Federal University of Goiás, Goiânia, GO, Brazil.

2 - Resident Physician in the Department of Orthopedics and Traumatology, Clinical Hospital of the Federal University of Goiás, Goiânia, GO, Brazil.

3 - Head of the Pediatric Orthopedics Group, Department of Orthopedics and Traumatology, Clinical Hospital of the Federal University of Goiás, Goiânia, GO, Brazil.

4 - Trainee from the Trauma Students' Association, Department of Orthopedics and Traumatology, Clinical Hospital of the Federal University of Goiás, Goiânia, GO, Brazil.

Work performed in the Department of Orthopedics and Traumatology, Clinical Hospital of the School of Medicine, Federal University of Goiás (UFG).

Correspondence: Departamento de Ortopedia, Hospital das Clínicas, Primeira Avenida, sem número, Setor Universitário, 74000-000 Goiânia, GO.

E-mail: frederico_barra@yahoo.com.br

Work received for publication: January 27, 2011; accepted for publication: July 12, 2011.

The authors declare that there was no conflict of interest in conducting this work 
gluteus and quadriceps muscles. He also presented major limitation of elbow and ankle flexion-extension. His gait was equine, with knee contracture, such that the right knee was stiff in flexion and left knee in extension.

Laboratory blood tests for calcium, phosphorus, alkaline phosphatase, urea, creatinine and parathyroid hormone found normal values. Imaging examinations (radiographs) showed several calcified lesions, heterotopic ossifications and bone bars in the lumbar spine (Figure 1A), cervical spine (Figure 1B), thoracic spine (Figure 2), pelvis (Figure 3) and knee (Figure $4 \mathrm{~A}$ and $\mathrm{B}$ ).
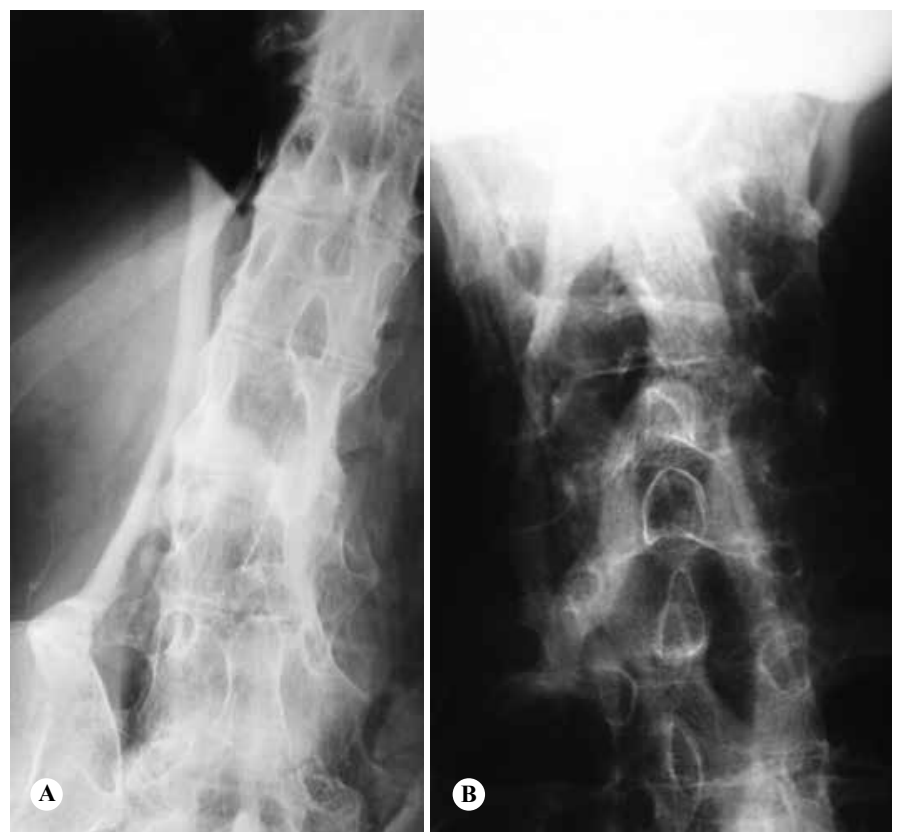

Figure 1 - Anteroposterior radiograph of the lumbar spine $(A)$ and cervical spine (B), showing paravertebral calcifications.

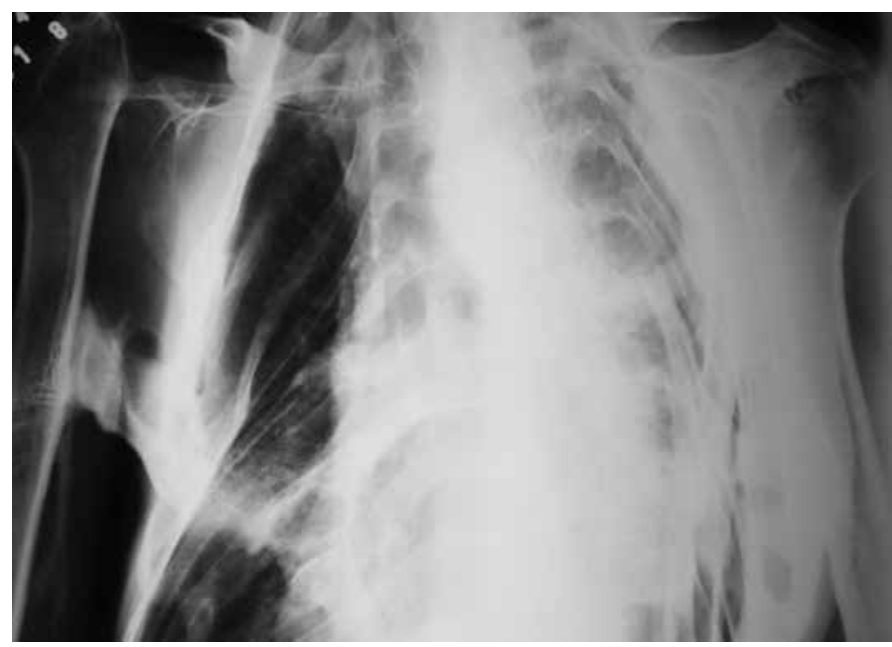

Figure 2 - Anteroposterior radiograph of the chest showing ectopic calcifications that limit thoracic inspiration.

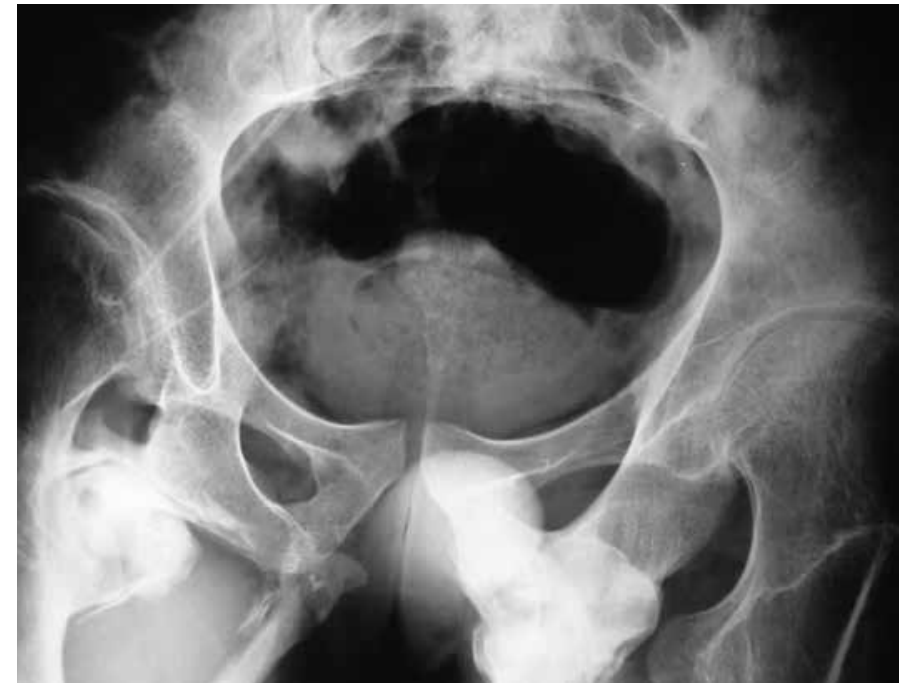

Figure 3 - Anteroposterior radiograph of the pelvis showing periarticular muscle calcification.

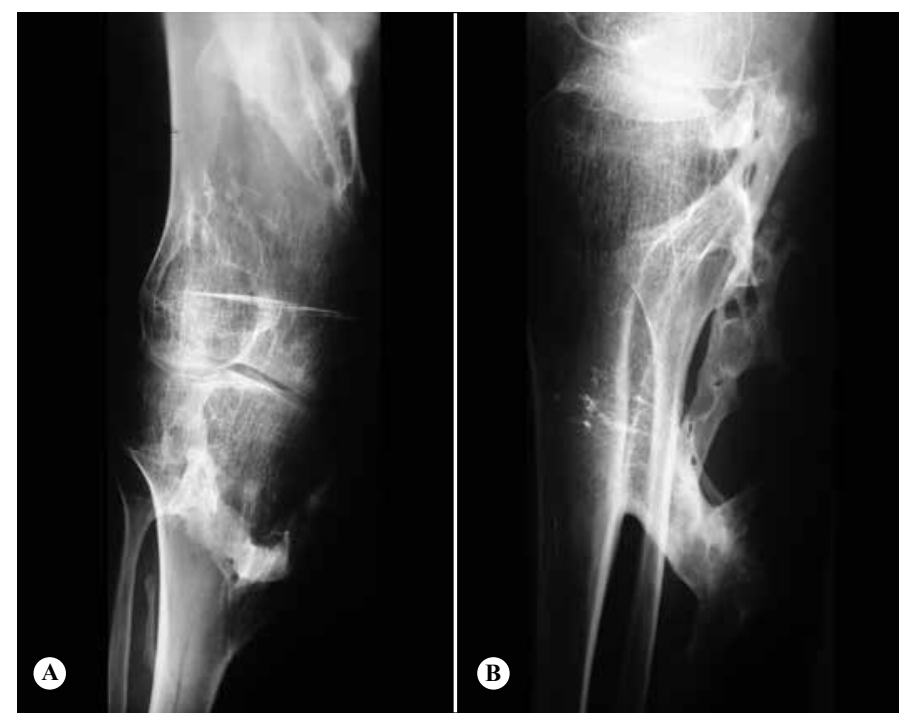

Figure 4 - Anteroposterior radiograph $(A)$ and lateral radiograph $(B)$ of the right knee, showing calcifications that lead to joint stiffness.

The treatment instituted was clinical, consisting of guidance to avoid trauma and referral for bisphosphonate and ascorbic acid therapy.

\section{DISCUSSION}

Correct early diagnosis of MOP is essential in order to allow appropriate management to start. Unnecessary biopsies and surgery should be avoided, as should intramuscular or intravenous injections, which might trigger or accelerate the inflammatory process, a phase that precedes ectopic calcifications. Intramuscular vaccines such as against diphtheria-tetanus-pertussis, measles, hepatitis-B, etc, can be applied subcutaneously ${ }^{(9)}$. Dental treatment should be 
done cautiously, avoiding anesthesia, particularly in the mandible, in order to prevent ankylosis of the temporomandibular joint ${ }^{(10)}$. Prophylaxis for dental caries is essential in order to avoid procedures that would be more aggressive. The physical activity that is most appropriate for MOP patients is swimming, even if with some limitations, since patients can adapt to the movements that they are still able to make. Thus, this is a means of doing physical exercise without the lesions resulting from impacts or direct trauma.

MOP can be seen on simple radiographs approximately two to four weeks after the process starts. The calcification starts on the periphery and progresses towards the center, which differentiates it from osteosarcoma. Computed tomography helps to delineate the central radiolucent area surrounded by peripheral density, in cases of $\mathrm{MOP}^{(11)}$.

The differential diagnosis is made with universal idiopathic calcinosis, dermatomyositis, tumoral idiopathic calcinosis and diseases due to changes in cal- cium metabolism. The presence of ossifications in the soft tissues of the axial skeleton and abnormalities in the fingers simplifies the diagnosis in cases of MOP.

Ascorbic acid seems to act in MOP cases towards stabilizing the disease ${ }^{(8)}$. Diminished ossification, possibly in transition, i.e. still within the inflammatory process, has been attributed to the action of ascorbic acid towards modulating the synthesis of procollagen III $^{(8)}$.

Regarding the treatments used so far, bisphosphonates are effective in relation to ossification that has already become established ${ }^{(12)}$. When there is a severe limitation on movements and gastric intolerance, use of intravenous bisphosphonate may be indicated and may produce a good improvement ${ }^{(12,13)}$.

Oral or intravenous administration of ascorbic acid and bisphosphonate may be an alternative for controlling and diminishing ectopic calcifications over the long term, thereby significantly improving these patients' quality of life.

\section{REFERENCES}

1. Whyte MP. Heritable metabolic and dysplastic bone diseases. Endocrinol Metab Clin North Am. 1990;19(1):133-73.

2. Patin G. Lettres choisis de feu M. Guy Patin. Letter of August 27, 1648, to AF. Cologne P. du Laurens, 1692. Tome 1, vol. 5, p. 28.

3. Reinig JW, Hill SC, Fang M, Marini J, Zasloff MA. Fibrodysplasia ossificans progressiva: CT appearance. Radiology. 1986;159(1):153-7.

4. Smith R, Russell RG, Woods CG. Myositis ossificans progressiva. Clinical features of eight patients and their response to treatment. J Bone Joint Surg Br. 1976;58(1):48-57.

5. Rogers JG, Dorst JP, Geho WB. Use and complications of high-dose disodium etidronate therapy in fibrodysplasia ossificans progressiva. J Pediatr. 1977;91(6):1011-4.

6. Bar Oz B, Boneh A. Myositis ossificans progressiva: a 10-year follow-up on a patient treated with etidronate disodium. Acta Paediatr. 1994;83(12):1332-4.

7. McEvoy GK. Unclassified therapeutic agents. In: American Hospital For-

mulary Service (AHFS) Drug Information. Bethesda, Library of Congress, 2000, 3399-403.

8. Palhares DB. Myositis ossificans progressive. Calcif Tissue Int. 1997;60(4):394.

9. Buyse G, Silberstein J, Goemans N, Casaer P. Fibrodysplasia ossificans progressiva: still turning into wood after 300 years? Eur J Pediatr. 1995;154(9):694-9.

10. Connor JM, Evans DA. Fibrodysplasia ossificans progressiva. The clinical features and natural history of 34 patients. J Bone Joint Surg Br. 1982;64(1):76-83.

11. Bullough P. Orthopaedic Pathology. 3a ed. London: Times Mirror International Publishers Limited; 1997.

12. Palhares DB, Leme LM. [A perspective on the control of myositis ossificans progressiva]. J Pediatr (Rio Janeiro). 2001;77(5):431-4.

13. Alpigiani MG, Puleo MG, Callegarini L, Di Bella E, Debbia C, Buzzanca C, et al. [Dichloromethylenbiphosphonic acid in the therapy of myositis ossificans progressive (MOP)]. Minerva Pediatr. 1996;48(4):159-63. 